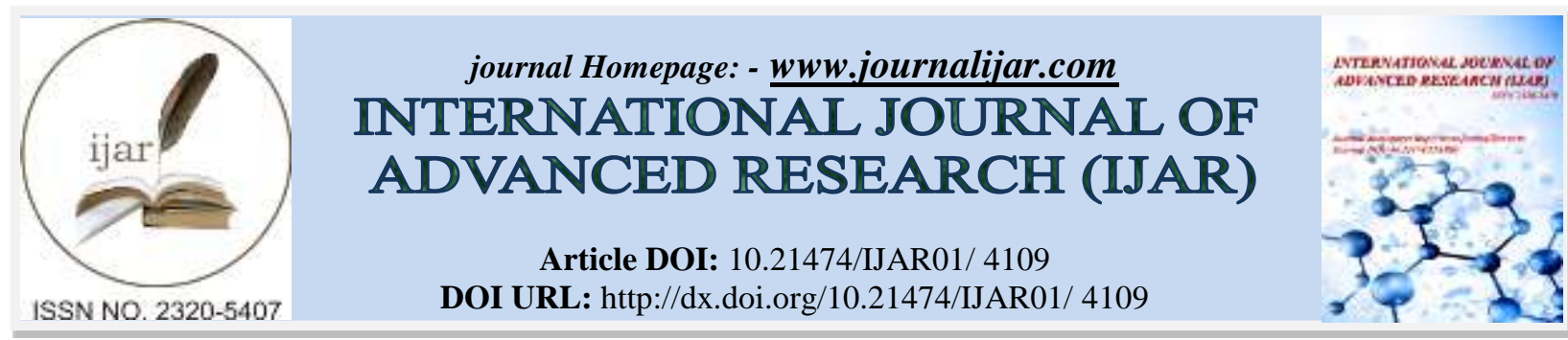

RESEARCH ARTICLE

\title{
POSTEROMEDIAL APPROACH TO THE DISTAL HUMERUS FOR TREATMENT OF THE MEDIAL COLUMN FRACTURES IN CHILDREN, TECHNICAL NOTE.
}

Ashraf Rashad Marzouk MD ${ }^{1}$ and Abdelaal Ahmed Hamed Kassem MSc ${ }^{2}$ and Ahmed Sleem MD ${ }^{2}$.

1. Lecturer of Orthopedic Surgery, Faculty of Medicine, Sohag University, Egypt.

2. Assistant lecturer of Pediatric Orthopedic Surgery, Faculty of Medicine, Sohag University, Egypt.

\section{Manuscript Info}

Manuscript History

Received: 12 March 2017

Final Accepted: 11 April 2017

Published: May 2017

\section{Abstract}

Aims: Exposure of the pediatric elbows for fixation of medial condylar and epicondylar fractures with or without dislocation is usually difficult through the direct medial approach due to the small sized elbows, associated marked edema which makes exposure of the ulnar nerve and direct visualization and reduction of the fracture difficult tasks in some cases, disruption of the ulnar collateral ligament and the flexor-pronator muscles during dissection, discomfort for the surgeon, improper insertion of Kirschner wires for definite fixation through the incision which makes the skin closure difficult, lastly; some surgeons bend the K. wires in attempt to protrude them through the skin away from the incision which may sometimes affect the reduction.

Methods: In order to overcome these difficulties we describe the posteromedial approach instead of direct medial approach for fractures which are actually posteromedial, this approach allows access to the fracture site by an incision directly over the ulnar nerve to avoid nerve traction or injury, it provides direct clear vision of the fracture site however the swelling is without disruption of ligaments, and allows easier insertion of $\mathrm{K}$. wires through the intact skin away from the incision.

\section{Conclusion:-}

Posteromedial approach to medial condyle is a good surgical option for open reduction and pinning or fixation of medial condylar fractures in children. It is safe, easy, extensile with good exposure of both the ulnar nerve and fracture site, and with less complications.

Copy Right, IJAR, 2016,. All rights reserved.

\section{Introduction:-}

Distal humerus fractures are common in children, mostly supracondylar, lateral condylar fractures, or less commonly medial epicondyle. Medial humeral epicondylar fractures account for about $12 \%$ of all elbow fractures. ${ }^{1}$ The medial epicondyle gives attachment to common flexor origin including flexor carpi radialis, flexor carpi ulnaris, flexor digitorum superficialis, palmaris longus, part of the pronator teres, and the ulnar collateral ligament. ${ }^{2}$ While some authors would prefer open reduction and internal fixation if the epicondyle is displaced by $2-5 \mathrm{~mm},{ }^{3}$ other studies have recently stated that conservative treatment may results in the same outcome. ${ }^{4},{ }^{5}$ It is widely accepted 
now that absolute indications for open reduction and internal fixation of medial epicondylar fractures are; incarceration of the epicondylar fragment in the elbow joint, entrapment of the ulnar nerve, marked instability, and open fracture, ${ }^{6}$ in addition to cases of high-energy trauma, elbow laxity or instability, and significant fracture displacement. ${ }^{5}$

Several difficulties had been noted during open reduction of medial condylar and epicondylar fractures during exposure and fixation using the direct medial approach, namely; difficult exposure of the ulnar nerve, difficult access to the fracture site, disruption of the ulnar collateral ligament and the flexor-pronator muscles during dissection, and difficult insertion of $\mathrm{K}$ wires through the skin without bending of the wires which might affect the reduction, or placement of the wires through the incision which is not favorable, placement of the scar over the bony prominence of medial epicondyle is also disfiguring and cumbersome.

In this study we describe the posteromedial approach to avoid these possible drawbacks.

\section{Positioning:-}

Lateral position is used, with the injured elbow is flexed on arm support. (Fig.1a)

- The surgeon sits or stands on the ulnar side of the elbow. A sterile tourniquet is utilized on the operated arm.

\section{Surgical approach:-}

A longitudinal skin incision about $4 \mathrm{~cm}$ long is made midway between the medial epicondyle and tip of olecranon, in the swollen injured elbow, the skin incision is made medial to the olecranon as the only landmark.(Fig.1b). and if the fracture is associated with dislocation closed reduction is mandatory before exposure.

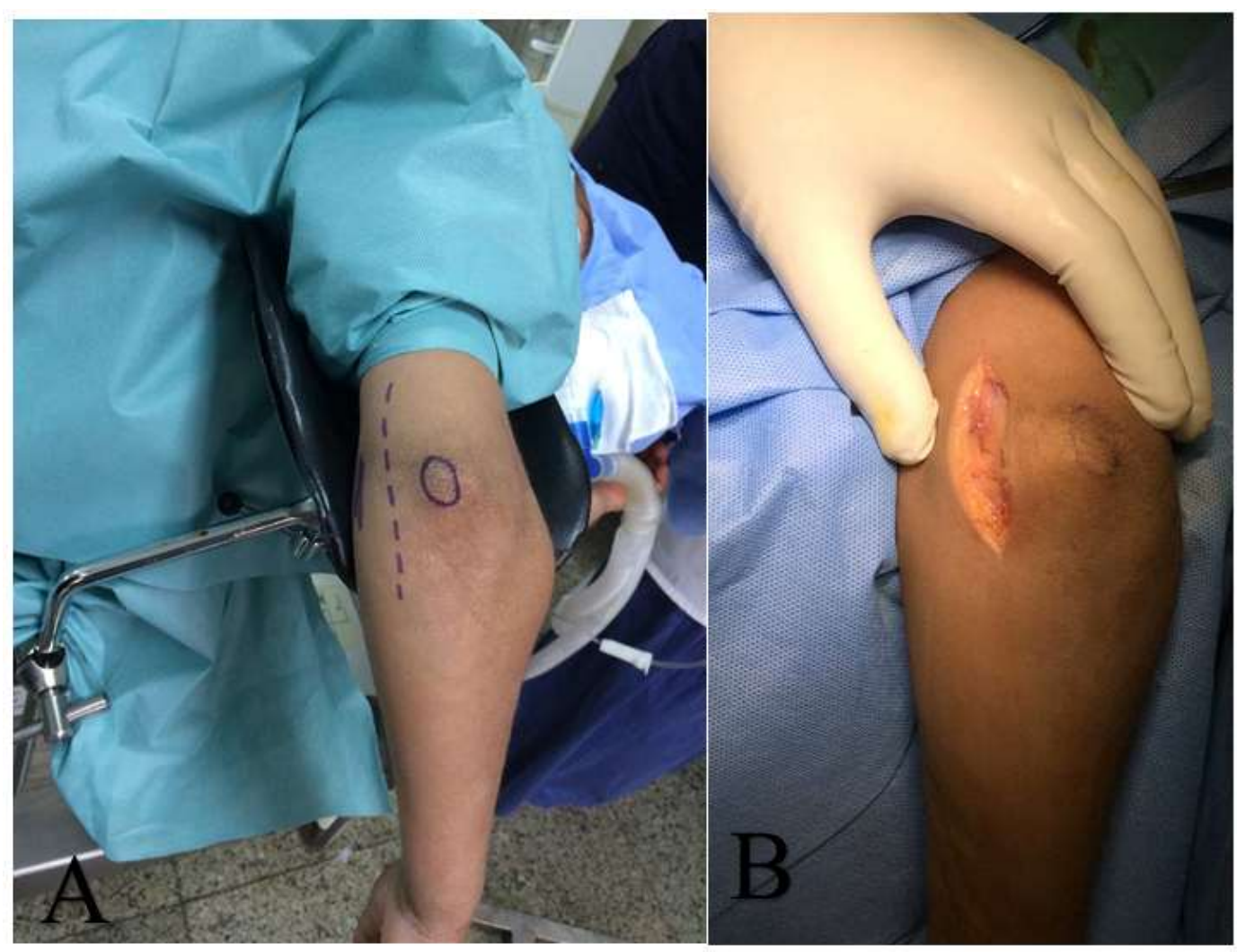

Figure 1:- A: shows lateral decubitus position of the patient.

B: shows the incision midway between the olecranon and medial epicondyle.

\section{Procedure:}

After skin incision the ulnar nerve is gently identified and exposed and retracted posteriorly. (Fig 2a). The displaced medial epicondyle is identified and reflected distally with a skin hook to expose the origin of the epicondyle fragment, (Fig.2b). The fracture site is curetted and refreshed to prevent soft tissue interposition which may hinder 
the fracture union. Reduction of the fracture is made under direct vision checked by fluoroscopy and held temporary by pointed forceps and then fixed by K. wire or cannulated screws with washers. (Fig.3a).

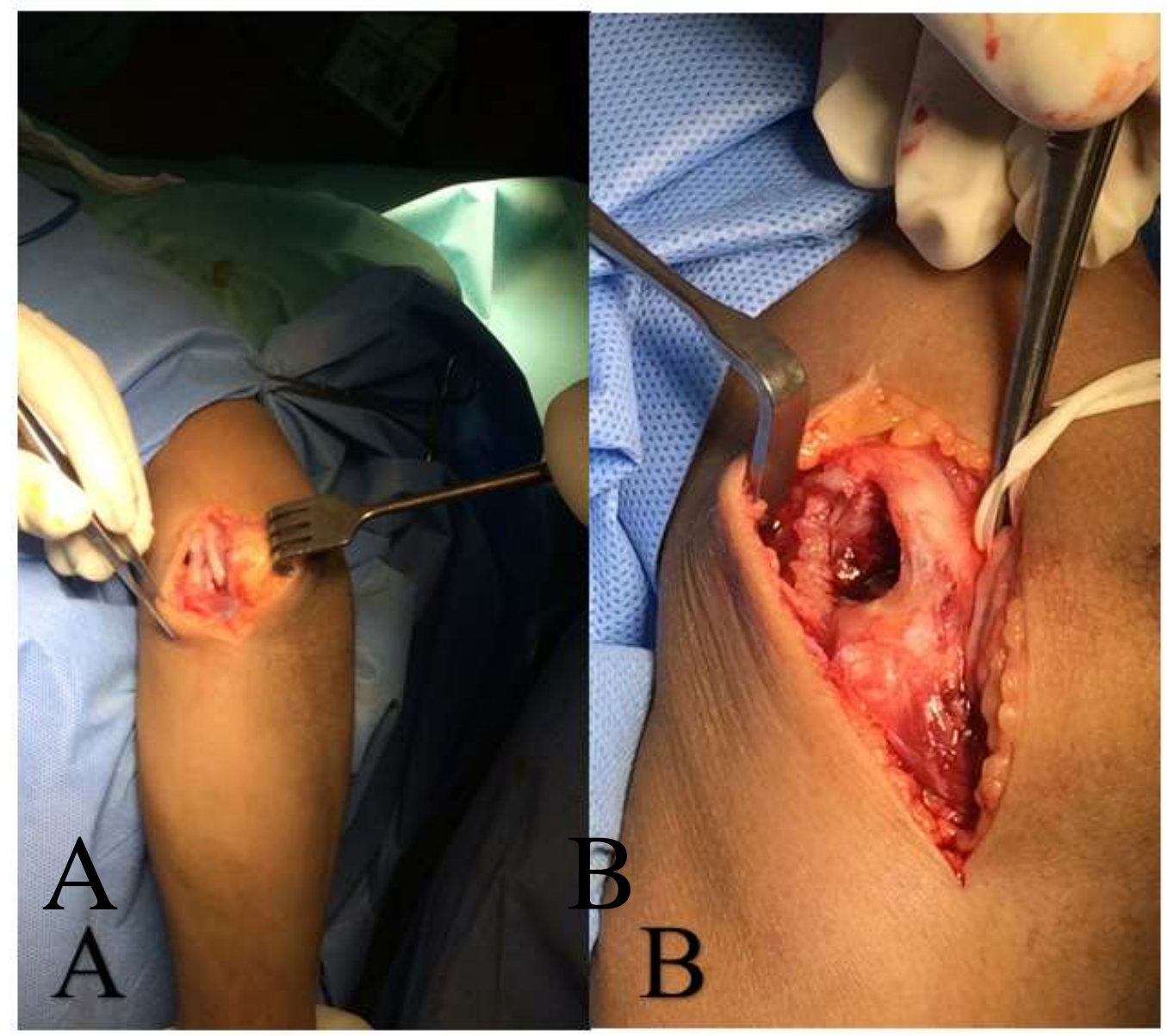

Figure 2:- A: Shows ulnar nerve after exploration

B: Shows ulnar nerve retracted and fracture site is exposed 


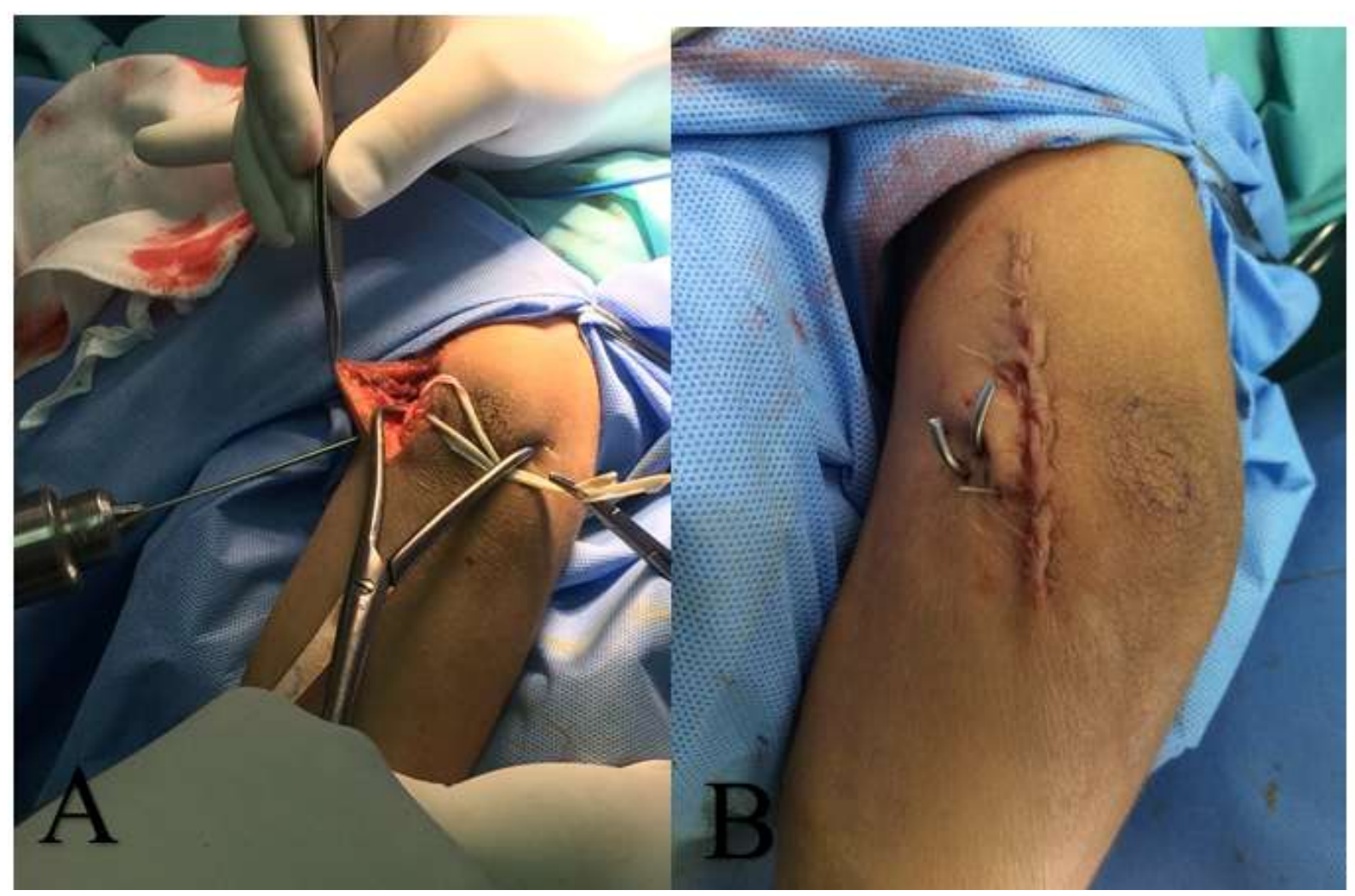

Figure 3 :- A: Shows percutaneous insertion of the K. wires after temporary holding by reduction forceps. B: Skin closure using interrupted sutures after fixation and assurance using image intensifier.

Care is taken to avoid drilling into the olecranon fossa. Anteroposterior and lateral views are obtained to assure proper reduction of medial epicondyle and optimal placement of $\mathrm{K}$. wires or screws and washers. The tourniquet is released and all bleeding spots is controlled. Closure of subcutaneous layer using absorbable sutures. The skin is closed with interrupted monocryl or nylon suture. (Fig.3b).

The arm is placed into a well-padded above elbow splint with the elbow at about $80^{\circ}$ of flexion and the forearm in supination.

\section{Postoperative care :-}

The splint is removed after 4 weeks postoperatively and elbow motion is started. Instruction and monitoring of motion, strengthening, and home exercises by parents or by aid of a physical therapist is recommended.

\section{Discussion:-}

Direct medial approach for open reduction of medial epicondylar fracture in children has been used as the standard approach. Many complications had been reported in literature after open reduction of medial epicondyle fracture, e.g, ulnar nerve injury, non union, infection, avascular necrosis due to interruption of blood supply to trochlea and medial epicondyle, technical difficulties due to difficult exposure of ulnar nerve, or presence of the scar over the bony prominence of medial epicondyle which might become cumbersome for children. Although not all these reported complications could be attributed to the direct medial approach, posteromedial approach seems to be less likely to have the same complications. It allows direct exploration and identification of the ulnar nerve, and retraction using surgical tape aiming at achieving a less incidence of ulnar nerve injury during open reduction of medial epicondylar fracture. 
Tenuous blood supply of trochlea is one of the major problems associated with the surgery of medial condyle of humerus. Blood supply of trochlea at this region is solely provided by terminal branches with no collateral supply. ${ }^{78}$ Blood flow may be easily disturbed if the soft tissue at the posterior of condyle is stripped off during the open surgery for exposure or reduction. ${ }^{9}$ This may lead to nonunion or avascular necrosis. Posteromedial approach could preserve the blood supply to the trochlea and medial condyl by less manipulation due to direct access of the fracture site with no traction over soft tissue flaps which carry the blood supply to trochlea and medial epicondyle. It allows easier percutaneous insertion of the wires and leave a cosmotic scar away from the bony prominence.

\section{Conclusion:-}

Posteromedial approach to medial condyle is a good surgical option for open reduction and pinning or fixation of medial condylar fractures in children. It is safe, easy, extensile with good exposure of both the ulnar nerve and fracture site.

\section{References:-}

1. Wilkins, K., Fractures and Dislocations of the Elbow Region; Iz Rockwood CA Jr., Wilkins KE i King RE: Fractures in Children. Philadelphia, JB Lippincott Company: 1991.

2. Silberstein, M.; Brodeur, A. E.; Graviss, E. R.; Luisiri, A., Some vagaries of the medial epicondyle. The Journal of Bone \& Joint Surgery 1981, 63 (4), 524-528.

3. Hines, R. F.; Herndon, W. A.; Evans, J. P., Operative treatment of Medial epicondyle fractures in children. Clinical orthopaedics and related research 1987, 223, 170-174.

4. Farsetti, P.; Potenza, V.; Caterini, R.; Ippolito, E., Long-term results of treatment of fractures of the medial humeral epicondyle in children. J Bone Joint Surg Am 2001, 83 (9), 1299-1305.

5. Lawrence, J. T. R.; Patel, N. M.; Macknin, J.; Flynn, J. M ;.Cameron, D.; Wolfgruber, H. C.; Ganley, T. J., Return to Competitive Sports After Medial Epicondyle Fractures in Adolescent Athletes Results of Operative and Nonoperative Treatment. The American journal of sports medicine 2013, 41 (5), 1152-1157.

6. Patel, N. M.; Ganley, T. J., Medial epicondyle fractures of the humerus: how to evaluate and when to operate. Journal of Pediatric Orthopaedics 2012, 32, S10-S13.

7. Bensahel, H.; Csukonyi, Z.; Badelon, O.; Badaoui, S., Fractures of the Medial Condyle of the Humerus in Children. Journal of Pediatric Orthopaedics 1986, 6 (4), 430-433.

8. Papavasiliou, V.; Nenopoulos, S.; Venturis, T., Fractures of the medial condyle of the humerus in childhood. Journal of pediatric orthopedics 1987, 7 (4), 421-3.

9. Ippolito ,E.; Tudisco, C.; Farsetti, P.; Caterini, R., Fracture of the humeral condyles in children: 49 cases evaluated after 18 - 45 years. Acta Orthopaedica Scandinavica 1996, 67 (2), 173-178. 